\title{
ATTITUDE TOWARDS ADVERTISING AMONG YOUNG ADULTS: A COMPARATIVE STUDY BY ETHNICITY
}

\author{
Hiram Ting* \\ Universiti Malaysia Sarawak \\ Ernest Cyril de Run \\ Universiti Malaysia Sarawak \\ Teck-Weng Jee \\ Swinburne University of Technology
}

\begin{abstract}
The purpose of this study is to determine the attitude of young adults towards advertising from the perspective of ethnicity. Specifically, it seeks to find out how young adults from the Iban, Chinese and Malay communities perceive advertising so as to understand the implication of ethnicity and culture on the subject matter. A seven-factor belief model is adopted to decompose the theory of reasoned action. As such, it provides theoretical basis to explain similarities and differences of beliefs and attitude towards advertising across the three ethnic groups. Given its quantitative stance, a questionnaire-based survey was administered at universities. 316 out of 400 copies were then collected for analyses. The findings show that despite cultural differences embedded in ethnicity, beliefs and attitude of the three ethnic groups towards advertising are found largely to be similar. They can only be set apart by the effect of beliefs on the formation of attitude towards advertising. Implications and future studies are provided.
\end{abstract}

Keywords: Advertising; Attitude; Belief; Culture; Ethnic; Young Adults.

\section{INTRODUCTION}

Advertising by nature is a socio-cultural phenomenon (Wang \& Sun, 2010). While it is commonly known to play a key role in economic development, it also stimulates societal activities, and affects even the manner people live (Pollay \& Mittal, 1993; Wang, et al., 2009). Given the rapid development of digital technology, younger generations are becoming more exposed to advertisement than those who were of the same age a decade ago (Purosothuman, 2008; Tai, 2007). Information computerization, especially seen in the Internet and social media, is believed to have accelerated the shaping of modern society (Kluver, 2000). As a result the ways they receive and convey messages, and develop relationships have changed drastically in recent years (Syrett \& Lammiman, 2004). This makes the understanding of young consumers' view about advertising more intricate but, at the same time, essential than ever before.

Corresponding author: Faculty of Economics and Business, Universiti Malaysia Sarawak, Jalan Datuk Mohd Musa, 94300, Kota Samarahan, Malaysia.Email: hiramparousia@gmail.com 
Cultural impact on advertising view has been well documented in marketing literature (Durvasula \& Lysonski, 2001; La Ferle, et al., 2008). In fact culture and advertising are profoundly connected with each other (Wang \& Sun, 2010). Given the scenarios of both communication technology and cultural effect, this study is aimed to investigate the attitude of young adults towards advertising in the contemporary setting. Understanding young adults is of particular interest because they are the most highly Internet-connected age group (Hargittai \& Hinnant, 2008). As culture is embedded in ethnicity, how young adults from different ethnic groups perceive advertising will be looked into. Therefore the three most dominant ethnic groups in Sarawak, namely the Iban, Chinese and Malay, which account for more than $80 \%$ of the total population in the state, are included in the study. It is believed that the attitude of the present young adults towards advertising, and the implication of cultural differences on the subject matter will be elucidated. Hence knowledge about advertising in the context of young consumers with multi-ethnic and cultural background will be extended.

\section{LITERATURE REVIEW}

\subsection{Attitude towards Advertising}

For many years, the topic of attitude towards advertising has received substantial attention in the marketing literature because such attitude has been shown to have effect on attitude towards specific advertisement, attitude towards brands and purchase intention (Ha, et al., 2011; MacKenzie \& Lutz, 1989; Mehta, 2000; Mittal, 1994; O'Donohoe, 1995). Attitude towards advertising is largely known as "a learned predisposition to respond in a consistently favourable or unfavourable manner to advertising in general" (Lutz, 1985, p. 16). In order to articulate the formation of attitude towards advertising, past studies have also delved into its antecedents and determinants in order to assess their relationships. One of the most recognized preceding variables found in earlier empirical studies is the belief about advertising. It is described as specific statement about the attributes of an object (Brackett \& Carr, 2001; Ducoffe, 1996; Pollay \& Mittal, 1993; Wang, et al., 2009). Hence, it is able to provide more explanation to attitude towards advertising. As such the theory of reasoned action (TRA) developed by Fishbein and Azjen (1980) is adapted to provide theoretical basis to investigate beliefs and attitude towards advertising in the present study.

The seven-factor belief model by Pollay and Mittal (1993) is adopted to construct beliefs about advertising. The model has been used extensively in advertising-related studies because of its relevance and validity (Korgaonkar, et al., 2000; Korgaonkar, et al., 2001; Munusamy \& Wong, 2007; Ramaprasad \& Thurwanger, 1998). Two dimensions are proposed in this model, and they are personal utility, which are made up by four factors, and socioeconomics, which are in turn made up by three factors. Among the seven factors, product information describes advertising as a provider of information. Social role and image reflects the belief that advertising affects people's lifestyle and development of social status. Hedonism or pleasure indicates that advertising can be amusing and entertaining. Good for the economy denotes the view that advertising facilitates economic activities and improves standard of living (Belch \& Belch, 2009). Notwithstanding its positive aspects, advertising is also criticized for promoting materialism, falsity and corrupting values especially among the youths. Therefore attitudes 
toward advertising are measured by both positive or negative beliefs about advertising (Singh \& Vij, 2007).

\subsection{Culture and Ethnicity}

Culture reveals group-wide patterns of human thoughts and practices (Drake, 1994; Lau, et al., 2001; Legoh'erel, et al., 2009). Goodenough (1971) described culture as a set of beliefs or standards, shared by a group of individuals that have an impact on the behaviour of an individual. Similarly, Hall (1976) defined it as "the way of life of people, for the sum of their learned behavioural patterns, attitudes, and material things" (p. 20). Ethnicity, in turn, involves a common cultural heritage, a sense of belongingness that is passed from one generation to another (Renzetti \& Curran, 1998). As ethnicity is a dominant embodiment of culture (Usunier, 2000), it is apparent that the beliefs, attitudes and behaviours of individuals are hinged upon the ethnic groups that they belong to (Legoh'erel, et al., 2009). Due to its prevailing influence, cultural value priorities can be seen in the manner of living in each ethnic group (Schwartz, 1999), and they become traditions and norms to advocate what is appropriate and what is not in various situations.

One specific and sizeable group of young-adult population in Malaysia is university students (De Run, et al., 2010; Mokhlis, 2009). Even though their income comes mainly from educational loans and parental contributions, they make up a substantial percentage in the country's population, and have a considerable level of purchasing power and influence now and again (Beard, 2003; Morton, 2002; Wolburg \& Pokrywcznski, 2002). As one of the most populous states in Malaysia, Sarawak is predominantly made up by the Iban (30\%), Chinese (27\%) and Malay (24\%) communities, and they hold distinctive ethnic identities and cultural values (De Run, 2007; Statistics, 2010). Hence, university students from these three ethnic groups are selected purposively to assess their present attitude towards advertising and find out the implication of cultural differences on such attitude.

\section{RESEARCH PROBLEM AND HYPOTHESES}

Notwithstanding the profound effect of culture, technological advancement, especially in the meteoric rise and use of digital products among the young adults, and its subsequent impact on them cannot be overlooked (Eze \& Lee, 2012; Waller \& Fam, 2000). This phenomenon is believed to have increased worldwide exchanges of information, including national and cultural resources (Al-Rodhan, 2006), thus intensifying human reliance and conformity. Despite having marketing-related studies which use ethnic groups in Sarawak as understudied samples (De Run, 2007; Ting \& De Run, 2012b; Ting, et al., 2012), little is known about the implication of culture on attitude of the present young adults towards advertising. Moreover, studies on advertising attitude of Malaysian young adults represented by university students are still found wanting when compared to the West (Munusamy \& Wong, 2007; Ramaprasad, 1994), and they do not necessarily show consistent results (De Run \& Ting, 2013; Kwek, et al., 2010; Ramaprasad, 1994; Rashid \& Sidin, 1987). Hence it is mandatory to keep up with the current view of this specific segment by ethnicity to gain insights on how they perceive advertising. 
Due to the differences of culture embedded in ethnic groups, it is postulated that the seven factors of belief about advertising across the Iban, Chinese and Malay young adults will be different; hence the following hypothesis:

\section{H1: Beliefs about advertising among the young adults across three ethnic groups will be significantly different.}

Since beliefs about advertising are postulated to be different, attitude towards advertising and the effect of beliefs on attitude towards advertising across the three ethnic groups will also be different; hence the following hypotheses:

H2: Attitude towards advertising among the young adults across three ethnic groups will be significantly different.

H3: The effect of beliefs about advertising on attitude towards advertising among the young adults across three ethnic groups will be different.

\section{METHODOLOGY}

Students from Universiti Malaysia Sarawak (UNIMAS) and Swinburne University of Technology Sarawak (SUTS) were chosen to constitute the population of the study. The former is the most populous public university and the latter the most populous private university with its own campus in Sarawak. Moreover, although these students are from all over Malaysia, Sarawakian students from different divisions and districts in the state can be easily found and approached on campus. Students who are from foreign countries and have outgrown young adulthood were not included in the study. Using past studies on young adults as a general guide, the age range of between 19 and 25 was used to describe young adults for this study.

Judgmental and snowball sampling approaches were used to ensure that the intended people were selected purposefully to accomplish the aim of the study (Onwuegbuzie \& Leech, 2007), and the numbers of students sampled from the three ethnic groups reflect the actual distribution of population in Sarawak (Ting \& De Run, 2012a). A self-administered questionnaire based survey was utilized to collect data. A seven-point Likert scale where 1 indicates 'strongly disagree' and 7 indicates 'strongly agree' was adopted for all items pertaining to beliefs and attitude towards advertising. All continuous items were randomized to address issues with common method variance. Before finalizing the questionnaire, a pre-test of 30 respondents using debriefing method was conducted to eliminate potential problems with questionnaire design, and ensure that the questions would accomplish what was expected of them (Bazera, 1996; Hunt, et al., 1982). A total of 400 copies were distributed on the two campuses concurrently by enumerators, and 316 usable copies were collected in two weeks time in March 2013. Data were then keyed-in into the Statistical Package for Social Science (SPSS) for subsequent analyses. 


\section{FINDINGS}

Table 1 shows the demographic details of 316 young adults sampled from the public and private universities. Given the number of questionnaire copies distributed and collected, a response rate of more than $60 \%$ is adequate to ensure survey quality and minimal effect of response error (Richardson, 2005; Nulty, 2008).

Table 1: Respondent Profile

\begin{tabular}{lcc}
\hline & Frequency & Percent \\
\hline Gender & & \\
Male & 132 & 41.8 \\
Female & 184 & 58.2 \\
Ethnic & & \\
Iban & 118 & 37.3 \\
Chinese & 105 & 33.2 \\
Malay & 93 & 29.4 \\
Age & & \\
19 & 21 & 6.6 \\
20 & 64 & 20.3 \\
21 & 81 & 25.6 \\
22 & 40 & 12.7 \\
23 & 40 & 12.7 \\
24 & 32 & 10.1 \\
25 & 38 & 12.0 \\
\hline
\end{tabular}

Descriptive analysis was used to obtain Mean values for the seven factors of belief and attitude towards advertising. They are presented both as an overall result and by ethnicity as shown in Table 2. In addition, Cronbach's alpha values for each factor are presented to indicate their reliability scores.

Table 2: Mean and Reliability Values by Ethnicity

\begin{tabular}{ccccccccccc}
\hline \multirow{2}{*}{ Factor } & \multirow{2}{*}{ Item } & \multicolumn{2}{c}{ Overall } & \multicolumn{2}{c}{ Iban } & \multicolumn{2}{c}{ Chinese } & \multicolumn{2}{c}{ Malay } & \multicolumn{2}{c}{$\begin{array}{c}\text { Cronb. } \\
\text { Alpha }\end{array}$} \\
\cline { 3 - 10 } & & Mean & S.D. & Mean & S.D. & Mean & S.D. & Mean & S.D. & \\
\hline Information & 3 & 5.52 & 1.03 & 5.48 & 1.00 & 5.48 & 1.04 & 5.62 & 1.07 & 79.6 \\
Social Role & 3 & 4.81 & 1.21 & 4.86 & 1.34 & 4.54 & 1.03 & 5.04 & 1.19 & 78.3 \\
Hedonism & 3 & 4.97 & 1.16 & 5.01 & 1.17 & 4.89 & 1.11 & 5.03 & 1.19 & 72.9 \\
Economy $_{\text {Materialism }}^{\mathrm{R}}$ & 3 & 4.92 & 1.15 & 4.89 & 1.23 & 4.78 & 1.10 & 5.10 & 1.07 & 79.5 \\
Falsity $^{\mathrm{R}}$ & 4 & 3.29 & 1.39 & 3.23 & 1.53 & 3.31 & 1.27 & 3.36 & 1.35 & 86.4 \\
Corruption $^{\mathrm{R}}$ & 3 & 3.47 & 1.35 & 3.42 & 1.39 & 3.54 & 1.37 & 3.46 & 1.29 & 84.6 \\
Attitude $^{2}$ & 3.57 & 1.30 & 3.51 & 1.28 & 3.62 & 1.32 & 3.60 & 1.31 & 78.8 \\
\hline & 3 & 4.92 & 0.93 & 4.90 & 0.95 & 4.86 & 0.88 & 5.02 & 0.96 & 73.6 \\
\hline
\end{tabular}

Notes: ${ }^{\mathrm{R}}$ indicates reverse-coding used therefore Materialism should read as Not Materialistic, Falsity as Truthfulness and Corruption as Not Corrupted to Youth 
In order to test whether the factors under investigation differ significantly across the three ethnic groups, one-way ANOVA with post-hoc comparison using the Duncan's range test was used. Table 3 shows the Mean and F values of beliefs and attitude towards advertising by ethnicity.

Table 3: Differences in Beliefs and Attitude towards Advertising by Ethnicity

\begin{tabular}{ccccc}
\hline Factor & Iban (Mean) & Chinese (Mean) & Malay (Mean) & F value \\
\hline Information & 5.48 & 5.48 & 5.62 & 0.622 \\
Social Role & 4.86 & $4.54 \mathrm{a}$ & $5.04 \mathrm{~b}$ & $4.491^{*}$ \\
Hedonism & 5.01 & 4.89 & 5.03 & 0.464 \\
Economy $^{\text {Materialism }}{ }^{\mathrm{R}}$ & 4.89 & 4.78 & 5.10 & 1.972 \\
Falsity $^{\mathrm{R}}$ & 3.23 & 3.31 & 3.36 & 0.228 \\
Corruption $^{\mathrm{R}}$ & 3.42 & 3.54 & 3.46 & 0.193 \\
Attitude $^{\text {atide }}$ & 3.51 & 3.62 & 3.60 & 0.248 \\
\hline
\end{tabular}

Notes: $* \mathrm{p}<0.05 ;{ }^{\mathrm{R}}$ indicates reverse-coding used therefore Materialism should read as Not Materialistic, Falsity as Truthfulness and Corruption as Not Corrupted to Youth. Means with different superscripts indicate that they are significantly different at $\mathrm{p}<0.05$. Means without superscripts are not significantly different from the Means with superscripts.

In order to assess the effect of each belief factor on attitude towards advertising, Multiple Linear Regression was used. Table 4 shows the effect of the seven factors of belief about advertising on attitude towards advertising by ethnicity.

Table 4: Effect of Beliefs about Advertising on Attitude towards Advertising by Ethnicity

\begin{tabular}{cccc}
\hline \multirow{2}{*}{ Factor } & \multicolumn{3}{c}{ Attitude } \\
\cline { 2 - 4 } & Iban (Beta) & Chinese (Beta) & Malay (Beta) \\
\hline Information & 0.091 & $0.429 * *$ & $0.300^{* *}$ \\
Social Role & $0.174^{*}$ & 0.000 & -0.021 \\
Hedonism & $0.235^{* *}$ & 0.106 & $0.219^{*}$ \\
Economy $_{\text {Materialism }}^{\mathrm{R}}$ & $0.294^{* *}$ & $0.201^{*}$ & $0.278^{* *}$ \\
Falsity $^{\mathrm{R}}$ & $0.278^{* *}$ & -0.081 & -0.056 \\
Corruption $^{\mathrm{R}}$ & -0.003 & $0.294^{* *}$ & 0.059 \\
\hline F value $_{\text {R }}^{2}$ & 0.038 & 0.123 & 0.013 \\
Adjusted R $^{2}$ & 11.613 & 13.329 & 9.107 \\
\hline
\end{tabular}

Notes: $* \mathrm{p}<0.05, * * \mathrm{p}<0.01$ (one-tailed); ${ }^{\mathrm{R}}$ indicates reverse-coding used therefore Materialism should read as Not Materialistic, Falsity as Truthfulness and Corruption as Not Corrupted to Youth. 


\section{DISCUSSIONS}

At the outset, the findings have shown young adults from the three ethnic groups, despite being culturally different, have similar level of agreement on beliefs about advertising. All of them agree that product information is the most dominant belief about advertising while social role, hedonism and good for a nation's economy are almost as important. They have also expressed their consensus on the negativity about advertising. They believe advertising is causing the society to become more materialistic, and is not necessary truthful. Although they are still in their early adulthood, they believe advertising can corrupt values among the youngsters.

However the only significant difference that can be observed in the test of difference is the belief about social role of advertising between the Chinese and Malay young adults. As the Malays generally put a lot of emphasis on Islamic faith and the way of life (Asmah, 1983), these young adults may have responded to the current social trend differently from the Chinese. Apart from that, it can be concluded that the beliefs of Iban, Chinese and Malay young adults about advertising are largely similar. However, due to the difference observed between the Chinese and Malay young adults on the social role of advertising, the first hypothesis is thus partially supported. Moreover, notwithstanding the profound impact of culture on values and behaviours, the attitudes of the Iban, Chinese and Malay towards advertising are found to be not significantly different. As such, the second hypothesis on the presupposed difference in attitude is not supported.

The last findings, in turn, infer that the specific beliefs that actually contribute to the formation of attitude towards advertising are likely to be dissimilar by ethnicity. Although such comparison does not imply empirical differences across ethnic groups, it is still useful in revealing which attribute of advertising has stronger effect on attitude towards advertising across the ethnic groups. Aside their similarities, the Ibans' attitude towards advertising tend to be more strongly affected by social role and materialistic aspect of the advertising. As for the Chinese, the falsity of advertising plays a major role in shaping their attitude towards advertising. The findings about the Malays do not seem to suggest there is any standout belief about advertising when compared to that of the Ibans and Chinese. This may well imply the three ethnic groups in Sarawak have mutually adopted their cultural resources, with the Malays being the most dominant ethnic group (Brumbaugh, 2002; De Run, 2007). Since the effects of beliefs on their attitude are observed to be dissimilar, the third hypothesis is thus supported.

\section{IMPLICATIONS AND CONCLUSION}

Despite being in different ethnic groups with distinctive cultural values and practices, the Iban, Chinese and Malay young adults seem to have shared common beliefs about advertising. Subsequently, they hold similar attitude towards advertising. Only the social role presented by advertising is found to be significantly different between the Chinese and Malay young adults. This may well suggest that the development of information technology in recent years have gradually infiltrated the stronghold of culture. Consequently, young adults begin to share their cultural resources, issuing in stronger mutual adoption of values and practices (Sorrells, 2012). This justifies why a common set of beliefs about advertising in a broader sense and in a national context which surpasses the boundary of ethnicity is found in this study. From 
the managerial perspectives, managers and marketers need to devise marketing strategy and advertising campaign meticulously to include what is shared across ethnic groups, and preclude what is not. In particular, when targeting the young adults who have extensive access to the Internet and digital products, it is imperative to know what attributes of advertising all ethnic groups believe and adopt. It is equally important to recognize what sets them apart and causes them to avert due to cultural differences. This will ensure advertising effectiveness in multi-cultural societies.

This study is limited in a sense that it only looks at attitude towards advertising in general. Moreover, it is conducted only in the state of Sarawak. As a result, the findings cannot be generalized to young adults in Malaysia as a whole and in other countries. Furthermore, the study does not provide empirical evidence on the causal link between the development of information technology and the impact of cultural values. Therefore, a nationwide study will be much needed to reassess the view of young adults about advertising in a more comprehensive manner in order to articulate the implication of technological phenomena and cultural adoption on this matter. Comparative studies between young and full adults, and adolescents can also be conducted so as to determine if generational differences play a part in defining the characteristics of the young adults.

\section{ACKNOWLEDGEMENT}

This paper is based on research at Universiti Malaysia Sarawak under Faculty Funded Research (Grant no: FPI (F01)/125/2012 (85)). The authors express their gratitude to UNIMAS for sponsoring the research carried out.

\section{REFERENCES}

Ajzen, I., \& Fishbein, M. (1980). Understanding Attitudes and Predicting Social Behavior. London: Prentice-Hall.

Al-Rodhan, N. R. F. (2006). Definitions of Globalization: A Comprehensive Overview and a Proposed Definition. Program on the Geopolitical Implications of Globalization and Transnational Security. Retrieved from http:/www.sustainablehistory.com/articles/ definitions-of-globalization.pdf

Asmah, O. (1983). The Phonological Diversity of the Malay Dialects. Kuala Lumpur: Dewan Bahasa dan Pustaka.

Bazera, M. S. (1996). Marketing Research for Planning, Monitoring and Marketing Design Making (1 ed.). Riyadh: Al-Obikan Press.

Beard, F. K. (2003). College Student Attitudes toward Advertising's Ethical, Economic, and Social Consequences. Journal of Business Ethics, 48(3), 217-228.

Belch, G. E., \& Belch, M. A. (2009). Advertising and Promotion: An Integrated Marketing Communications Perspective (8 ed.). New York: McGraw Hill.

Brackett, L., \& Carr, B. (2001). Cyberspace Advertising vs. Other Media: Consumer vs. Mature Student Attitudes. Journal of Advertising Research, 41(5), 23-32. 
Brumbaugh, A. M. (2002). Source and Nonsource Cues in Advertising and Their Effects on the Activation of Cultural and Subcultural Knowledge on the Route to Persuasion. Journal of Consumer Research, 29(2), 258-269.

De Run, E. C. (2007). Constructing Ethnic Identification Variables of Malay, Chinese and Iban. The ICFAI Journal of Marketing and Management, 6(3), 38-52.

De Run, E. C., \& Ting, H. (2013, 25-26 June 2013). Attitude of Marketing and Non-marketing Students towards Advertising. Paper presented at the Global Conference on Business, Economics and Social Sciences, Kuala Lumpur.

De Run, E. C., Butt, M., \& Nee, C. Y. (2010). The Influence of Role Models on Young Adults Purchase. Jurnal Kemanusiaan, 15, 70-81.

Department of Statistics. (2010). Total Population by Ethnic Group, Sub-district and State, Malaysia, 2010. Retrieved 23 July, 2012, from http://www.statistics.gov.my/portal/ download_Population/files/population/05Jadual_Mukim_negeri/Mukim_Sarawak.pdf

Drake, L. E. (1994). Cultural Determinacy in Negotiation. East Lansing, MI: Michigan State University.

Ducoffe, R. (1996). Advertising Value and Advertising on the Web. Journal of Advertising Research, 36(5), 21-35.

Durvasula, S., \& Lysonski, S. (2001). Are There Global Dimensions of Beliefs toward Advertising in General: A Multicultural Investigation. In C. P. Rao (Eds.), Globalization and its Managerial Implications (pp. 184-202). Westport, CT: Quorum Books.

Eze, U. C., \& Lee, C. H. (2012). Consumers' Attitude towards Advertising. International Journal of Business and Management, 7(13), 94-108.

Goodenough, W. H. (1971). Culture, Language and Society. Reading, MA: Addison-Wesley.

Ha, H.-Y., John, J., Janda, S., \& Muthaly, S. (2011). The Effects of Advertising Spending on Brand Loyalty in Services. European Journal of Marketing, 45(4), 673-691.

Hall, E. (1976). Beyond Culture. Garden City, NY: Doubleday Anchor Books.

Hargittai, E., \& Hinnant, A. (2008). Digital Inequality: Differences in Young Adults' Use of the Internet. Communication Research, 35(5), 602-621.

Hunt, S. D., Sparkman, R. D. J., \& Wilcox, J. B. (1982). The Pretest in Survey Research: Issues and Preliminary Findings. Journal of Marketing Research, 19(2), 269-273.

Kluver, R. (2000). Globalization, Information, and Intercultural Commnication. American Communication Journal, 3(3), 1.

Korgaonkar, P. K., Karson, E. J., \& Lund, D. (2000). Hispanics and Direct Marketing Advertising. Journal of Consumer Marketing, 17(2), 137-157.

Korgaonkar, P. K., Silverblatt, R., \& O'Leary, B. (2001). Web Advertising and Hispanics. Journal of Consumer Marketing, 18(2), 134-152. 
Kwek, C. L., Tan, H. P., \& Lau, T. C. (2010). The Determinants of Consumers' Attitude towards Advertising. Canadian Social Science, 6(4), 114-126.

La Ferle, C., Edwards, S., \& Lee, W. (2008). Culture, Attitudes, and Media Patterns in China, Taiwan, and the U.S. Balancing Standardization and Localization Decisions. Journal of Global Marketing, 21(3), 191-205.

Lau, I., Chiu, C., \& Lee, S. (2001). Communication and Shared Reality: Implications for the Psychological Foundations of Culture. Social Cognition, 19, 350-371.

Legoh'erel, P., Dauc'e, B., Hsu, C. H. C., \& Ranchhold, A. (2009). Culture, Time Orientation, and Exploratory Buying Behavior. Journal of International Consumer Marketing, 21(2), 93-107.

Lutz, R. J. (1985). Affective and Cognitive Antecedents of Attitude towards Ad: A Conceptual Framework. In L. F. Alwitt \& A. A. Mitchell (Eds.), Psychological Processes and Advertising Effects (pp. 45-63). Hillsdale, NJ: Lawrence Erlbaum.

MacKenzie, S. B., \& Lutz, R. L. (1989). An Empirical Examination of the Structural Antecedents of Attitude toward the Ad in an Advertising Pretesting Context. Journal of Marketing, 53(2), 48-65.

Mehta, A. (2000). Advertising Attitudes and Advertising Effectiveness. Journal of Advertising Research, 40, 67-72.

Mittal, B. (1994). Public Assessment of TV Advertising: Faint Praise and Harsh Criticism. Journal of Advertising Research, 34(1), 35-53.

Mokhlis, S. (2009). An Investigation of Consumer Decision-Making Styles of Young-Adults in Malaysia. International Journal of Business and Management, 4(4), 140-148.

Morton, L. P. (2002). Segmenting Baby Boomers. Public Relations Quarterly, 46(3), 46-47.

Munusamy, J., \& Wong, C. H. (2007). Attitude towards Advertising among Students at Private Higher Learning Institutions in Selangor. Unitar E-journal, 3(1), 31-51.

Nulty, D. D. (2008). The Adequacy of Response Rates to Online and Paper Surveys: What Can be Done? Assessment and Evaluation in Higher Education, 33(3), 301-314.

O'Donohoe, S. (1995). Attitudes to Advertising: A Review of British and American Research. International Journal of Advertising, 14(3), 245-261.

Onwuegbuzie, A. J., \& Leech, N. L. (2007). Sampling Designs in Qualitative Research: Making the Sampling Process More Public. The Qualitative Report, 12(2), 238-254.

Pollay, R. W., \& Mittal, B. (1993). Here's the Beef: Factors, Determinants, and Segments in Consumer Criticism of Advertising. Journal of Marketing, 57, 99-114.

Purosothuman, N. P. (2008). Key Determinants of Virtual Store Acceptance among the Malaysians Consumers. Master Degree, Universiti of Malaya.

Ramaprasad, J. (1994). Personalized interactions and generalized beliefs about advertising: the case of Malaysian students. Paper presented at the Conference of the American Academy of Advertising, Athens, GA. 
Ramaprasad, J., \& Thurwanger, M. L. (1998). South Asian Students Attitudes toward and Beliefs about Advertising: Measuring Across Cultures. Paper presented at the AEJMC Annual Conference, Baltimore.

Rashid, M. Z. A., \& Sidin, S. M. (1987). The Structure of Students' Attitudes Towards Advertising. Paper presented at the Southeast Asia Conference of the Academy of International Business, Kuala Lumpur.

Renzetti, C. M., \& Curran, D. J. (1998). Living Sociology. Boston: Allyn and Bacon.

Richardson, J. T. E. (2005). Instruments for Obtaining Student Feedback: A Review of the Literature. Assessment and Evaluation in Higher Education 30(4), 387-415.

Schwartz, S. H. (1999). A Theory of Cultural Values and Some Implications for Work. Applied Psychology: An International Review, 48(1), 23-47.

Singh, R., \& Vij, S. (2007). Socio-Economic and Ethical Implications of Advertising - A Perceptual Study. Paper presented at the International Marketing Conference on Marketing \& Society, IIMK.

Sorrells, K. (2012). Intercultural Communication Globalization and Social Justice. Thousand Oaks: Sage Pubs.

Syrett, M., \& Lammiman, J. (2004). Advertising and Millennials. Young Consumers, 3, 62-73.

Tai, S. H. C. (2007). Correlates of Successful Brand Advertising in China. Asia Pacific Journal of Marketing and Logistics, 19(1), 40-56.

Ting, H., \& De Run, E. C. (2012a). Generations X and Y Attitude towards Controversial Advertising. Asian Journal of Business Research, 2(2), 18-32.

Ting, H., \& De Run, E. C. (2012b, 24-25 September). Identifying Generational Cohorts in Sarawak: A Comparison between Three Ethnic Groups. Paper presented at the International Conference Series, Taylor's University Lakeside Campus, Subang Jaya.

Ting, H., De Run, E. C., \& Fam, K.-S. (2012, 19-21 December). Identifying Generational Cohorts in Sarawak. Paper presented at the 5th International Borneo Business Conference, Tawau.

Usunier, J. C. (2000). Marketing across Cultures (3 ed.). Harlow, England: Pearson Education.

Waller, D. S., \& Fam, K.-S. (2000). Cultural Values and Advertising in Malaysia: Views from the Industry. Asia Pacific Journal of Marketing and Logistics, 12(1), 3-16.

Wang, Y., \& Sun, S. (2010). Assessing Beliefs, Attitudes, and Behavioral Responses toward Online Advertising in Three Countries. International Business Review, 19(4), 333-344.

Wang, Y., Sun, S., Lei, W., \& Toncar, M. (2009). Examining Beliefs and Attitudes toward Online Advertising among Chinese Consumers. Direct Marketing: An International Journal, 3(1), 52-66.

Wolburg, J. M., \& Pokrywcznski, J. (2002). A Psychographic Analysis of Generation Y College Students. Journal of Advertising Research, 41(5), 33-52. 